\title{
Locating on-street loading and unloading spaces by means of mixed integer programming
}

\author{
Bruno de Athayde Prata ${ }^{1}$, Leise Kelli de Oliveira ${ }^{2}$, Thiago Costa Holanda ${ }^{3}$ \\ 1Departament of Industrial Engineering, Federal University of Ceará, baprata@ufc.br \\ 2Departament of Transportation and Geotechnical Engineering, Federal University of Minas Gerais, leise@etg.ufmg.br \\ ${ }^{3}$ Municipal Secretary of Transit in Fortaleza, thiagoholanda1@hotmail.com
}

\section{Recebido:}

16 de dezembro de 2015

Aceito para publicação:

14 de novembro de 2017

Publicado:

30 de abril de 2018

Editor de área:

Claudio Barbieri da Cunha

\section{Keywords:}

Urban freight transport, Loading/unloading places, Mixed integer programming, Facility location problem.

\section{Palavras-chaves:}

Transporte urbano de cargas,

Áreas de carga e descarga, Programação inteira mista, Problema de localização de facilidades.

DOI:10.14295/transportes.v26i1.1051

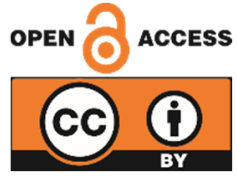

\begin{abstract}
In an urban freight distribution system, determination of the number and location of loading-unloading places is required to regulate loading-unloading operations. This paper presents mathematical models for on-street loading-unloading space location based on set-covering problem and $p$-median problem formulations. The approaches was tested with real data: an area has 160 city blocks and 60 on-street loading-unloading spaces, in Fortaleza, Brazil. We evaluated four scenarios considering different radius of influence of a loading/unloading spaces. The results indicate this approach has potential for achieving gains in terms of reduction of the distance between the clients and the loading and unloading places: considering that the average distance is a performance indicator (ratio between the total distance and the covered clients), a radius of influence of 400 meters has best relation (0.489) and all clients are covered. The results indicate that the model can be used by planners to allocate loading and unloading areas.
\end{abstract}

\section{RESUMO}

Em um sistema de distribuição de carga urbana, é necessária a determinação do número e da localização dos locais de carga e descarga para regular as operações de carga e descarga. Este artigo apresenta modelos matemáticos para a localização do espaço de carga e descarga na rua com base no problema de cobertura e formulação de problemas de p-mediana. A abordagem foi testada com dados reais: uma área tem 160 quadras e 60 áreas de carga e descarga, em Fortaleza, Brasil. Avaliamos quatro cenários considerando diferentes raios de influência das áreas de carga/descarga. Os resultados indicam que esta abordagem tem potencial para obter ganhos em termos de redução da distância entre os clientes e os locais de carga e descarga: considerando que a distância média é um indicador de desempenho (relação entre a distância total e os clientes cobertos), um raio de influência de 400 metros tem melhor relação $(0.489)$ e todos os clientes estão cobertos. Os resultados indicam que o modelo pode ser usado pelos planejadores para alocar áreas de carga e descarga.

\section{INTRODUCTION}

Urban goods movement is important because it is directly related to the lives of city dwellers and the increasing problem of congestion in central urban areas. Crainic et al. (2004) suggest that the main factors contributing to this phenomenon are current production and distribution based on low level of inventory and just-in-time deliveries, as well as the growth of electronic commerce, which generates a significant volume of home deliveries. These strategies increase the frequency distribution of orders for retailers and consequently exacerbate problems with freight vehicle parking in urban centres.

Dablanc (2007) defines urban goods distribution as multiple flows entering, crossing and leaving urban areas. According to Ogden (1992), urban freight transport is the goods movement to, from, within and through urban areas, and urban freight transport is part of the supply chain, and its coverage area extends beyond city limits (Browne et al., 2007). 
Lack and inappropriate use of loading and unloading spaces is one of main problems to urban freight transport (Oliveira, 2014). Aiura and Taniguchi (2005) note that the provision and management of loading-unloading spaces for freight vehicles are important issues in urban areas. Even in areas where these spaces exist, passenger vehicles often occupy them. In Tokyo, passenger cars use approximately 54\% of parking spaces and freight vehicles use $22 \%$ (Aiura \& Taniguchi, 2005). Similarly to Tokyo, in Belo Horizonte, passenger cars occupied $56 \%$ of the loading-unloading area and freight vehicles occupied only $37.5 \%$ of them, which are not always in operation (Oliveira, 2014; Oliveira \& Guerra, 2014). In this context, it is essential to implement measures aimed at sustainable development of cities through resolution of urban freight transport problems (Taniguchi et al., 2001), reducing the inefficiencies and improving the effectiveness of the system through innovative solutions that reduce logistical problems (Oliveira et al., 2010).

The current legislation in Brazil states that a loading-unloading operation should be carried out on the road but outside the traffic area. The allocation of areas for this service plays an important role in urban planning. Annex I of the Brazilian Traffic Code defines the loading-unloading operation as the immobilisation of the vehicle by the time needed to load or unload freight or animals, regulated by a board or executive authority competent to transit administrative division on the road.

Article 1 of the same law considers the operation of loading and unloading as traffic. In addition, Article 47 delegates the regulation of the operation of loading and unloading to agency or entity with administrative division on the road, and, it is considered parking. Furthermore, Article 48 regulates that vehicles should be positioned in the flow direction, parallel to the roadway and along the pavement, on the stops or parking places, with properly marked exceptions. The vehicles stopped, parked or in operation of loading or unloading shall be located outside of the roadway on the roads provided with roadside.

The third article of Law No. 12.587 of January 3th 2012, establishing the National Policy on Urban Mobility, considers freight displacements as part of the national system of urban mobility. The third item, the loading and unloading spaces comprise the infrastructure of urban mobility. Article 22 of the Brazilian Traffic Code considers the planning and management of urban mobility system, controlling the use and operation of road infrastructure for the movement and operation of freight transport, giving priorities or restrictions assignment of administrative agencies.

According to current legislation in Brazil, the operation of loading and unloading is performed onstreet. However, the space for movement and the pavement designed for pedestrians and others must be respected, since to realise the loading-unloading operation it is essential that the vehicle 'parks'. Considering that the street is designed for 'traffic', i.e., the movement of vehicles, people and animals, the obstruction of a street by a loading and unloading operation constitutes a traffic infraction. Thus, it is the responsibility of the municipal government, and essential for planning and management, that reserved areas for loading and unloading should be located outside the roadway.

In this context, this paper presents mathematical models for on-street loading and unloading space location based on set covering and $p$-median problems. We evaluate the effectiveness of these model in real situation to analyse applicability in urban planning. This paper is structured as follows. Section 2 provides a literature review. Mixed integer programming problems are presented in Section 3, with methodological approach. The results are presented in Section 4. Section 5 concludes and offers suggestions for future research.

\section{LITERATURE REVIEW}

According to Schroeder et al. (2014), freight models focus on certain aspects of the model object and do not map all relevant logistics decisions. Moreover, there is still a lack of models that assess policy measures with any sensitivity. Taniguchi et al. (2014) observe that modelling of city logistics schemes is required to evaluate the effects of implementing such measures. Recently, modelling has focused on three important areas: emissions, health care and mega-cities. To Taniguchi et al. (2001), models play a 
central role with the systems approach to city logistics because they permit estimates on the effects of various changes in the urban distribution system to be made without changing the system. According to Taniguchi et al. (2001), city logistics constitutes both a challenge and an opportunity in terms of methodological developments and actual social impact to operations research and transportation science,

To Comi et al. (2012), a general methodology capable of simulating urban freight transport should consist of a set of models which (1) forecast how the key activities of land use, the use of transport systems and associated markets may be expected to change over time, taking into account the transport infrastructure and its performance; (2) forecast the freight quantities requested by end-consumers through the simulation of shopping mobility; (3) simulate the distribution process of the various decision-makers; (4) represent the transportation infrastructures with their operation characteristics (supply models) and describe how to modify supply in order to optimise given objectives while respecting given constraints; (5) assign multi-commodity flows to a multimode network and (6) estimate and evaluate the performances and the impacts of a given city logistics scenario. Our study applies this methodology, focusing on the optimisation of freight transport operations.

Taniguchi et al. (2001) maintain that location analysis is important in city logistics schemes. Absi et al. (2012) point out that the city logistics facility location problem mainly addresses solutions for only two stakeholders: (1) carriers who want to optimise the location of their logistics platforms and the organisation of their distribution scheme and (2) local authorities who want to evaluate the relevance of available zones for the setting-up of distribution platforms or comparing different distribution scenarios in the city.

Thus, it is essential to identify policies and private initiatives that are beneficial to urban distribution activities, to make them more efficient and to reduce the social and environmental impacts that these operations cause (Browne et al., 2007). Crainic et al. (2009) emphasise that new models for managing freight distribution in cities have been proposed to mitigate the problems arising from this activity. These models mainly relate to the notion of city logistics, which considers the urban environment (shippers, carriers and society) and the integrated logistics system to be optimised. Taniguchi et al. (2003) established the concept of city logistics as the process of optimising transport and logistics activities in urban areas by considering the traffic, congestion and energy consumption within the economic structure. Tamagawa et al. (2010) consider it important to implement city logistics measures for effective and environmentally friendly transport to combat the very negative impact of trucks on the environment.

In this context, many scholars state the efficiency and effectiveness of urban freight distribution relates, among other things, to the rational use of on-street loading and unloading spaces in urban areas for goods distribution (Ogden, 1992; Visser et al., 1999; Taniguchi et al., 2001; Pivo et al., 2002; Janet, 2004; Munuzuri et al., 2005; Antun et al., 2007; Figliozzi, 2007; Taniguchi \& Tamagawa, 2005; Dasburg \& Schoemaker, 2006; Allen et al., 2008; McLeod \& Cherrett, 2011; Comi et al., 2012; Jaller et al., 2013). Ogden (1992) points out that the type and availability of places for loading and unloading operations can impact on the total cost of the process.

Taniguchi and Tamagawa (2005), Oliveira and Guerra (2014) and Oliveira (2014) point out the lack of rationalisation implies a high occupancy rate for other types of vehicles. In Brazil, one of the main problems facing transport operators is the difficulty of finding a place in a central area that is designated for parking and loading or unloading goods (Oliveira, 2014). Few parking places in Latin American cities are regulated to freight transport. Buenos Aires created 750 areas in 2009 (Dablanc, 2009). There are 550 areas in central Belo Horizonte but without guidelines to implementation (Oliveira, 2014). Dablanc (2009) points out that guideline in Europe are favourable to bigger spaces. In Paris, on-street delivery areas must be at least 10 metres long to facilitate truck manoeuvres and the handling of goods. There must be a minimum of one delivery bay per every 100 metres in the city streets, which has resulted in 10,000 regulated areas for urban distribution operations. Barcelona has a global policy for freight street management and 8,000 bays. Operator movement throughout the region affects the capacity of the surrounding roads and road safety (Aiura \& Taniguchi, 2005). 
Aiura and Taniguchi (2005) developed a facility location model to determine the optimal location of on-street loading-unloading spaces, minimising the total cost: it includes penalties for late delivery, fixed cost, operating cost, percentage of parking and cost of delivery vehicles and passenger cars. The model consists of two sub-models: (1) a model for spatial localisation of spaces for loading and unloading and (2) a simulation model for freight and passenger vehicles in an urban road network. Using a test network, the model was able to determine a configuration of parking areas that achieved a cost reduction of approximately $16 \%$.

Loureiro et al. (2012) developed a procedure for the location and allocation of loading-unloading spaces in urban centres using facility location model. The procedure consists of the identification and characterisation of the study area, the characterisation of the delivery sector, determination of the frequency of delivery or demand of commercial establishments and the definition of the service level desired. After defining the input parameters and identifying the potential places to install the facilities, the procedure determines the location and allocation of spaces by means of the set-covering problem. It was applied to a test area in the city of Campinas, Brazil and the results indicated 27 loading and unloading spaces were required to meet the demand for 56 points located in the study area. The authors used two models of location-allocation sequence (a complete coverage model and a maximum coverage model), but there was no significant improvement in the quality of the results, which could be explained by the small amplitude of the estimated values.

Jaller et al. (2013, p.4) showed 'insight into the freight parking problem in a large congested area to get a sense about the balance between the demand for parking generated by freight activity, and the onstreet supply of parking spaces'. Jaller et al. (2013, p.4) proposed a methodology to 'estimate commercial parking demand and space availability. Parking demand is estimated as a function of the truck trips produced and attracted by commercial establishments, while on-street parking space availability for freight deliveries is assumed to be a function of curb space dimensions and vehicle characteristics'. The results of this study suggest that alternatives such as parking pricing may not solve the problem as it is not caused by the misbehaviour of truck drivers. In general, there are not enough parking spaces.

Brasileiro et al. (2014) used queue theory to analyse vehicle parking on public roads. The authors treated public car parking on urban roads, the vehicle arrival process and the treatment process of the vehicles as stochastic. The rate of congestion was represented as service level. The methodology was utilized in Ilha Solteira, Brazil, whose commercial centre does not have a particular area for loading and unloading agricultural goods. Most vehicles (68\%) take 20 minutes for loading and unloading parked operations. The results indicated that a queue would form during the operations of loading and unloading. In this case, the specific area for parking, loading and unloading would not be sufficient to meet the demand.

Using another approach, Boussier et al. (2010) analysed the spatial and temporal dynamics of booking on-street stopping places (to park or to deliver). This paper uses multi-agent modelling of the management process of shared parking places between car drivers and dedicated areas for goods deliveries. McLeod and Cherrett (2011) identified reduced delivery times resulting from the use of bookable loading bays in urban areas for delivery and service vehicles. The analysis of the advance booking and control system models was programmed in Fortran and based on the rules and assumptions relating to the city of Winchester (UK).

Table 1: Summarize of on-street loading-unloading approach based on literature review

\begin{tabular}{lll}
\hline Approach & Goal/objective & Reference \\
\hline Facilities location model & Minimize total cost & Aiura and Taniguchi (2005) \\
\hline Facility location and set-covering approach & $\begin{array}{l}\text { Minimize number of loading-unloading spaces } \\
\text { and maximize demand }\end{array}$ & Loureiro et al. (2012) \\
\hline Freight trip generation & $\begin{array}{l}\text { Estimate commercial parking demand and } \\
\text { space availability }\end{array}$ & Jaller et al. (2013) \\
\hline Queue theory & Congestion rate as service level indicator & Brasileiro et al. (2014) \\
\hline
\end{tabular}


Table 1 summarize approach to analyse on-street loading-unloading models. In this context, our proposed approach bridges the literature gap regarding on-street loading-unloading models to optimise urban goods distribution, focused mainly on facility location models.

\section{METHODOLOGICAL APPROACH}

Since the 1990s, several authors have reported studies related to the application of mathematical models for facility location problems (ReVelle \& Eiselt, 2005). This class of problems has a strong combinatorial nature, so that solutions generated manually by the planners usually lead to low-quality solutions; therefore, operation research models and techniques are required to solve location problems. The mathematical models used to represent the above-mentioned problems in the scope of urban planning and logistics include the set-covering problem and the $p$-median problem (Larson \& Odoni, 1981; Klose \& Drexl, 2005; Sittipong et al., 2014).

The literature review has shown that the use of mathematical models for location of loading and unloading spaces is rare. Larson and Odoni (1981) proposed an algorithm to determine the optimal number of facilities in urban problems. The limitation of this procedure is that one cannot guarantee the existence of a feasible solution. In several real problems it does not exist, because the covering depends on quality criteria. One can adopt a radius of influence for the covering of clients, which does not permit the attendance of all clients, and a set-covering problem does not obtain a solution.

In our study, we have designed models to overcome this limitation, considering some practical assumptions of the problem and preserving the usefulness of the models (at least for some situations that are interesting in practice). We propose a relaxation of the set-covering problem and $p$-median problem, i.e., clients not allocated any facility are feasible. It is undesirable not to attend to a client. Thus, this situation is penalised in the objective function. Figure 1 presents the steps of our methodological proposal detailed below.

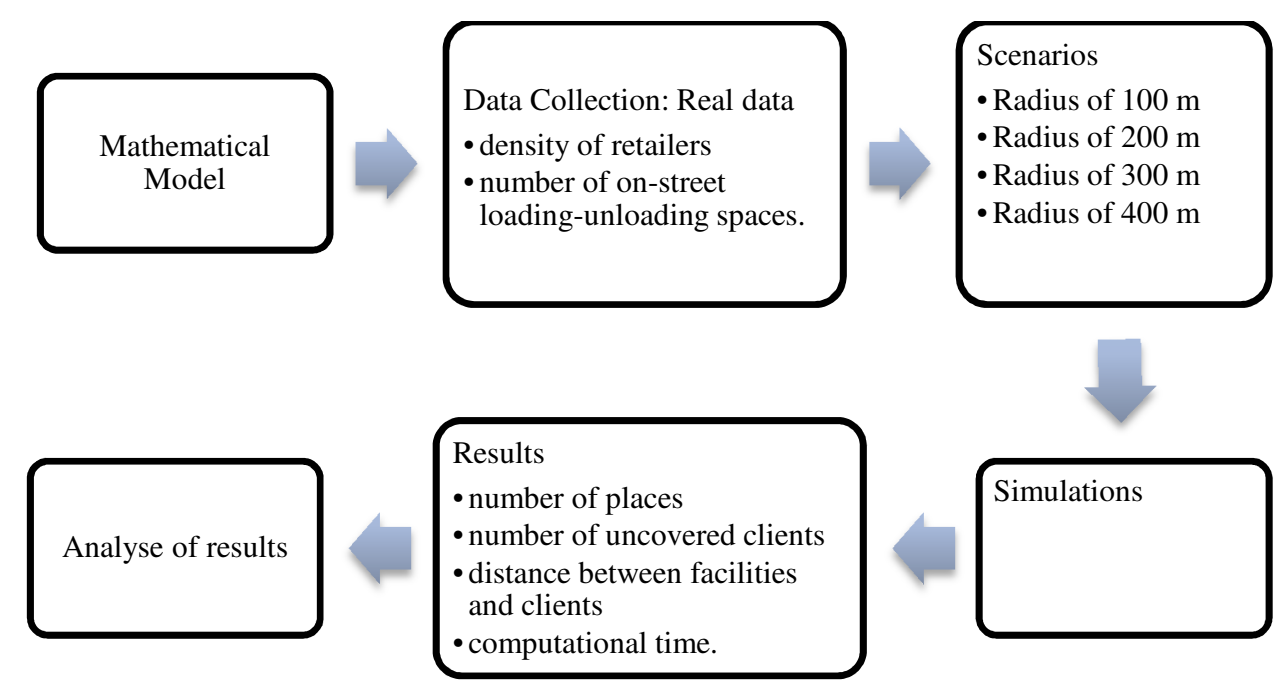

Figure 1: Steps of methodological approach.

\subsection{Mathematical model}

In this model, we introduce some notation for the proposed model based on the set covering problem, where we have two sets, $M$ and $N$, which represent the clients and the places, respectively. In addition, we have two important parameters, $s_{i}$, which represent the penalty factor for uncovering the $i^{\text {th }}$ client and $R$, which designates the radius of influence for each facility; in our study, it expresses the quality criteria. 
We intend to obtain the optimal quantity of on-street loading-unloading spaces and cover the maximum number of clients. We consider the relaxed unicost set-covering problem and let $A$ be a matrix representing the coverage relationships, with $a_{i j} \in\{0,1\}$. The above-mentioned problem is meant to determine the minimal number of loading and unloading places and covers the maximum number of clients. The variables of the model are as follows.

Binary decision variables:

$$
\begin{gathered}
x_{j}=\left\{\begin{array}{c}
1, \text { ifthe }^{\text {th }} \text { spaceis } \in \text { thesolution } \\
\text { 0, otherwise }
\end{array}, \forall j \in N\right. \\
Z_{i}=\left\{\begin{array}{c}
1, \text { ifthe }^{\text {th }} \text { clientisuncoveredbyaspace } \in \text { thesolution } \\
0, \text { otherwise }
\end{array}, \forall i \in M\right.
\end{gathered}
$$

Considering the objective of model intends to minimise the number of loading-unloading places, the problem can be formulated as follows.

subject to

$$
\begin{gathered}
\text { Minimizez }=\sum_{j=1}^{n} x_{j}+\sum_{i=1}^{m} S_{i} z_{i} \\
\sum_{j=1}^{n} x_{j}+\sum_{i=1}^{m} s_{i} z_{i}
\end{gathered}
$$

$$
\begin{array}{cc}
\forall i=1, \ldots, m . \\
x_{j} \in\{0,1\} \quad \forall j=1, \ldots, n . \\
z_{i} \geq 0 \quad \forall i=1, \ldots, m .
\end{array}
$$

The number of rows in this matrix is the number of clients and the number of columns is the number of loading-unloading spaces. The objective function (1) minimises the number of loading-unloading spaces. If the $i^{\text {th }}$ client is not covered, constraint (2) implies that $z_{i}$ equals one. Consequently, the integrality of the $z_{i}$ variables can be relaxed. Finally, constraints (3) and (4) define the scope of the model variables.

It should be noted that $z$ variables can be considered auxiliary variables, since they are not actually and effectively associated with decisions. If $z_{i}=1$, then there is an uncovered client. After the determination of the optimal number of facilities, one can obtain those which are closer to the clients, minimising the freight handling in the city centre. Additionally, some notation is introduced for the proposed model that is based on the $p$-median problem. Thus, consider an asymmetric $p$-median problem with covering constraints.

Sets

$$
\begin{aligned}
& M \text { - clients } \\
& N \text { - places }
\end{aligned}
$$

\section{Parameters}

$R$ - radius of influence for each facility (quality criteria)

$s_{i}$ - penalty factor for uncovering the $i^{\text {th }}$ client

$d_{i j}$ - distance from the $i^{\text {th }}$ client to the $j^{\text {th }}$ place

Binary decision variables

$$
\begin{gathered}
1, \text { ifthe }^{\text {th }} \text { isallocated } j^{\text {th }} \text { space } \\
x_{i j}=\{0, \text { otherwise }, \forall i \in M \wedge \forall j \in N \\
y_{i}=\left\{\begin{array}{c}
1, \text { ifthe }^{\text {th }} \text { spaceisamedian } \\
0, \text { otherwise }
\end{array}, \forall j \in N\right.
\end{gathered}
$$




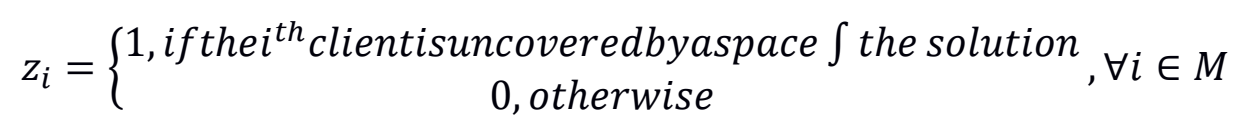

The objective of model intends to minimise the freight handling distances between places and clients, the problem can be formulated as follows.

$$
\text { Minimizez }=\sum_{i=1}^{m} \sum_{j=1}^{n} d_{i j} X_{i j}+\sum_{i=1}^{m} S_{i} z_{i}
$$

subject to

$$
\begin{gathered}
\sum_{j=1}^{n} x_{i j}+z_{i}=1, \forall i=1, \ldots, m . \\
x_{i j}+y_{i}+z_{i} \leq 0, \forall i=1, \ldots, m \wedge \forall j=1, \ldots, n . \\
\sum_{j=1}^{n} y_{i}=p \\
x_{i j} \in\{0,1\}, \forall i=1, \ldots, m \wedge \forall j=1, \ldots, n . \\
y_{j} \in\{0,1\}, \forall j=1, \ldots, n . \\
z_{i} \geq 0, \forall i=1, \ldots, m .
\end{gathered}
$$

The objective function (5) minimises the distances between the clients and the selected facilities. Clients not covered imply a penalisation in the objective function. If $i^{\text {th }}$ client is not covered, constraint (2) implies that $z_{i}$ equals one. Consequently, the integrality of the $z_{i}$ variables can be relaxed. Constraint (6) requires that a client is allocated to one median. Constraint (7) prohibits a client being allocated in a facility which is not a median. Constraint (8) bounds the maximum number of medians. Finally, constraints (9), (10) and (11) define the scope of the model variables.

\section{CASE STUDY}

The proposed modelling was applied in a real-world problem in Brazil in order to validate it. Fortaleza, the capital of Ceará, is a rapidly growing city. Located in north-eastern Brazil, Fortaleza has approximately 2,452,185 inhabitants distributed over $314.9 \mathrm{~km}^{2}$, with a population density of 7.78 inhabitants per $\mathrm{km}^{2}$. It is the largest city of Ceará in terms of population, with one-fifth of the total population of Brazil. Fortaleza is the ninth largest city in terms of GDP and has a fleet of 908,074 vehicles, 56\% of which are cars and $8 \%$ are freight vehicles. The metropolitan region of Fortaleza has 3.8 million inhabitants distributed in 15 municipalities.

The city centre is an area characterised by narrow streets with permission for parking on the right side. Due the density of commercial activities (wholesale and retail), bottlenecks in these pathways are a recurring problem. Unfortunately, the urbanisation of the city centre did not keep pace with the economic growth of the city, resulting in contiguous buildings and narrow pavements, usually occupied clandestinely by retailers. Thus, there is inadequate space for loading-unloading operations. Little attempt has been made to mitigate this problem. Government actions have been isolated and uncoordinated, and have not solved the real problem.

According to Lima et al. (2005), freight vehicles that usually park for loading-unloading operations in a traditional wholesale centre in the city centre take, on average, 9 hours and 48 minutes to perform loading-unloading activities. Policies that mitigate these negative impacts are very important in Fortaleza.

In this context, the mathematical programming approach can be used as a decision support tool, building several decision.

The model presented in (1) to (11) were modelled with the IBM ILOG CPLEX Optimization Studio version 12.6.0.0. The simulations were performed on a PC with Intel Core i5 3.2GHz and 8GB memory. 


\subsection{Data}

In order to evaluate the effectiveness of the model, it is necessary collect data from a commercial region with loading/unloading area. In this case, it is necessary to define a region, count number of commercial establishments and number of loading/unloading area.

The first step was to define an area with large commercial activity. In the selected area, there is a density of retailers and several parking and traffic problems. The selected region has 160 city blocks and 60 on-street loading-unloading spaces.

The data concerning the location of the loading-unloading places (facilities) were gathered by a survey in loco. A government-supplied list of addresses was made available. Subsequently, a survey in loco was conducted to confirm places in current operation. Data on a total of 458 stores were compiled in an address list, available on the Internet.

Addresses of places and stores were inserted with the Google Maps@ tool to obtain a matrix with the UTM coordinates of these points. A distance matrix $D[458,60]$ was calculated by a Euclidean metric. From the distance matrix a covering matrix $C[458,60]$ was obtained, which was calculated as follows. Element $C[i, j]$ equals one if the distance $d_{i j}$ between the $i^{\text {th }}$ client and the $j^{\text {th }}$ on-street space was less than or equal to the desired service level, and zero otherwise.

\subsection{Results}

We consider a parameter that can reflect the quality of the loading-unloading service. This criterion is the radius of influence of a place (facility). This parameter was tested for four scenarios: $100 \mathrm{~m}, 200 \mathrm{~m}$, $300 \mathrm{~m}$ and $400 \mathrm{~m}$. These scenarios impacted on other features of the solution, such as the number of places, the number of uncovered clients, the distance between facilities and clients and the computational time.

The computational results are presented in Tables 2 and 3, as follows: (i) $r$ : radius of influenca of a given loading and unloading place; (ii) $p$ : number of facilities in a given solution; (iii) $u$ : uncovered clients,, i.e. clients which are not attended by a selected facility; (iv) $c$ : percentage of clients attended by a selected facility; $t$ : computational times, expressed in seconds; (v) $T$ : total distance, i.e. summation of the distances between the clients and the selected facilites; and (vi) $A$ : average distance, i.e. the division of the total distance by the number of covered clients.

Table 2: Scenarios for relaxed set-covering problem

\begin{tabular}{llllll}
\hline Scenario & $\boldsymbol{r}(\mathbf{m})$ & $\boldsymbol{P}$ & $\boldsymbol{u}$ & $\boldsymbol{c}(\%)$ & $\boldsymbol{t}(\mathbf{s})$ \\
\hline 1 & 100 & 29 & 186 & $59 \%$ & 0,02 \\
2 & 200 & 18 & 40 & $91 \%$ & 0.02 \\
3 & 300 & 11 & 4 & $99 \%$ & 0.01 \\
4 & 400 & 8 & 0 & $100 \%$ & 0.02 \\
\hline
\end{tabular}

Table 3: Scenarios for asymmetric $p$-median problem with covering constraints

\begin{tabular}{llllll}
\hline Scenario & $\boldsymbol{r}(\mathbf{m})$ & $\boldsymbol{P}$ & $\boldsymbol{D}(\mathbf{k m})$ & $\boldsymbol{A}(\mathbf{m})$ & $\boldsymbol{t}(\mathbf{s})$ \\
\hline 1 & 100 & 29 & 14.8 & 54.4 & 0.11 \\
2 & 200 & 18 & 47.1 & 112.7 & 0.23 \\
3 & 300 & 11 & 67.6 & 148.9 & 0.42 \\
4 & 400 & 8 & 89.6 & 195.6 & 3.49 \\
\hline
\end{tabular}

The ratio of the average distance and the radius provides a performance indicator that can be applied to compare scenarios, just as the coefficient of variation is used in statistics. The average distance is a performance indicator of the solutions obtained, which is given by the ratio between the total distance (provided by the objective function) and the covered clients. The average distance varies between zero 
(the client is closer to the space) and the radius (the maximal distance). The smaller the average distance, the better the performance indicator.

In the figures, the red markers represent the load/unload places, the blue markers represent the clients and the hatched areas represent the influence area of a selected facility. Scenario 1 is illustrated in Figure 2. It has the following performance indicators: 29 selected facilities (loading-unloading places), operating with a radius of influence of $100 \mathrm{~m}$, enabling the coverage of $59 \%$ of the retailers. In this layout, there are several uncovered customers, implying the necessity of parking in non-regulated spaces for the delivery of urban freight at a desirable service level (in this scenario, a maximum distance of $100 \mathrm{~m}$ ).

Scenario 2 is illustrated in Figure 3. Here it can be observed that with a reduced service level (in this scenario, a maximum distance of $200 \mathrm{~m}$ ), the coverage of the retailers is greater than in Scenario 1 (in this case, $91 \%$ coverage).

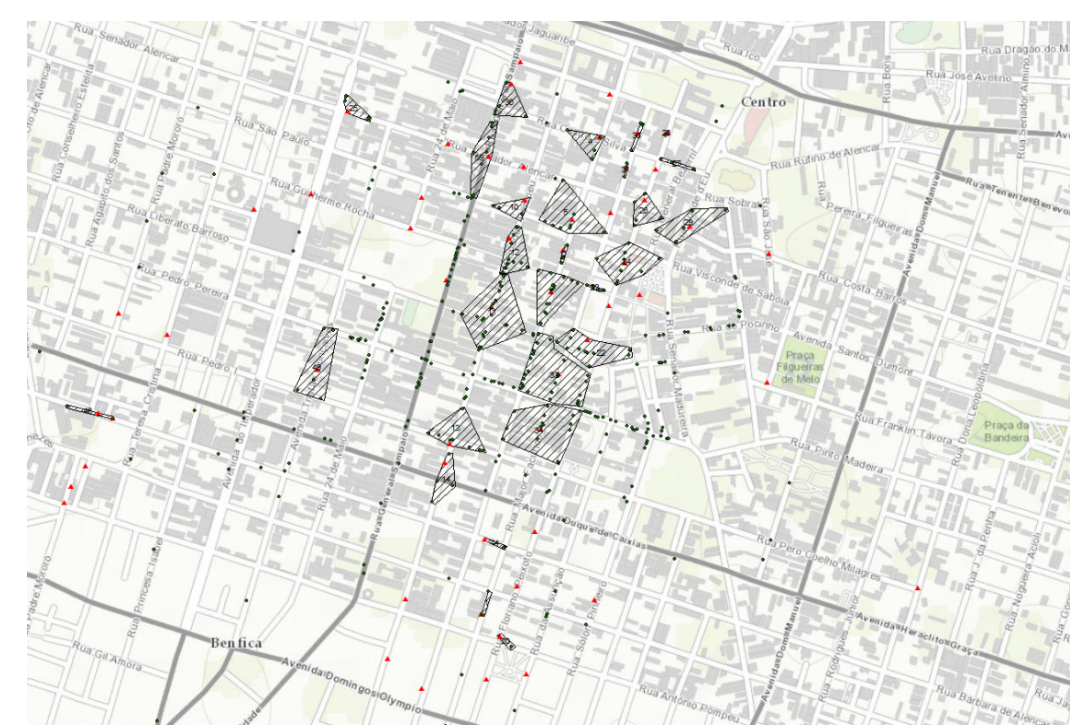

Figure 2: Spatial configuration of loading/unloading spaces in Scenario 1

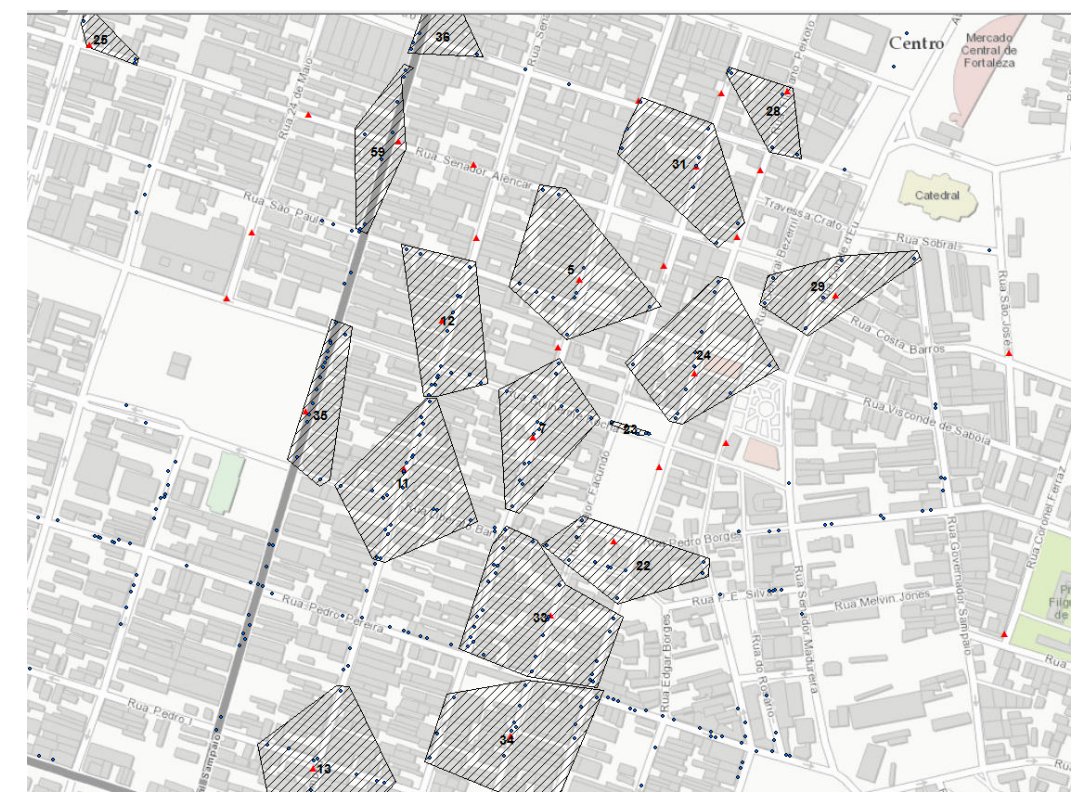

Figure 3: Spatial configuration of loading-unloading spaces in Scenario 2

Scenarios 3 and 4 are illustrated in Figures 4 and 5, respectively. In these scenarios, attendance is full, but lower service levels obtain for the customers (a maximum distance of $300 \mathrm{~m}$ and 400 for Scenarios 
3 and 4, respectively). In these scenarios, the operational time for delivery of the freight tends to increase because this distance needs to be walkable by the driver carrying the goods. At the same time, a parked vehicle could make a greater number of deliveries in the same loading-unloading space, which could represent an improvement in some cases.

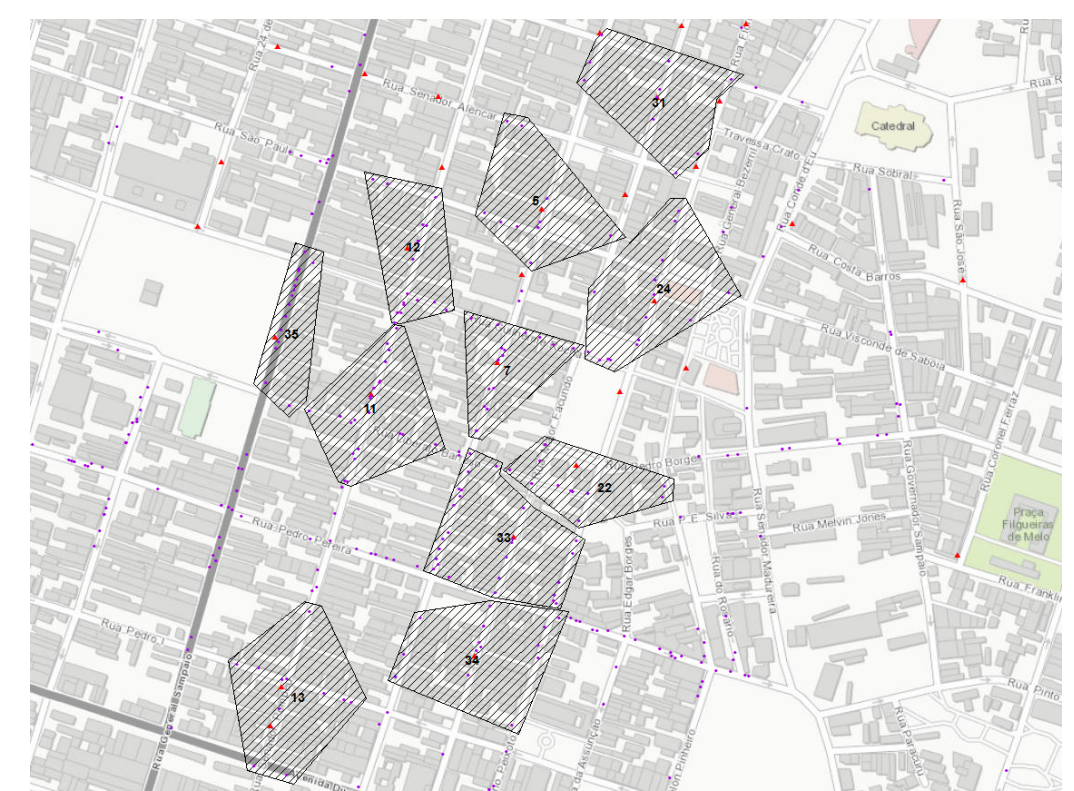

Figure 4: Spatial configuration of loading/unloading spaces in Scenario 3

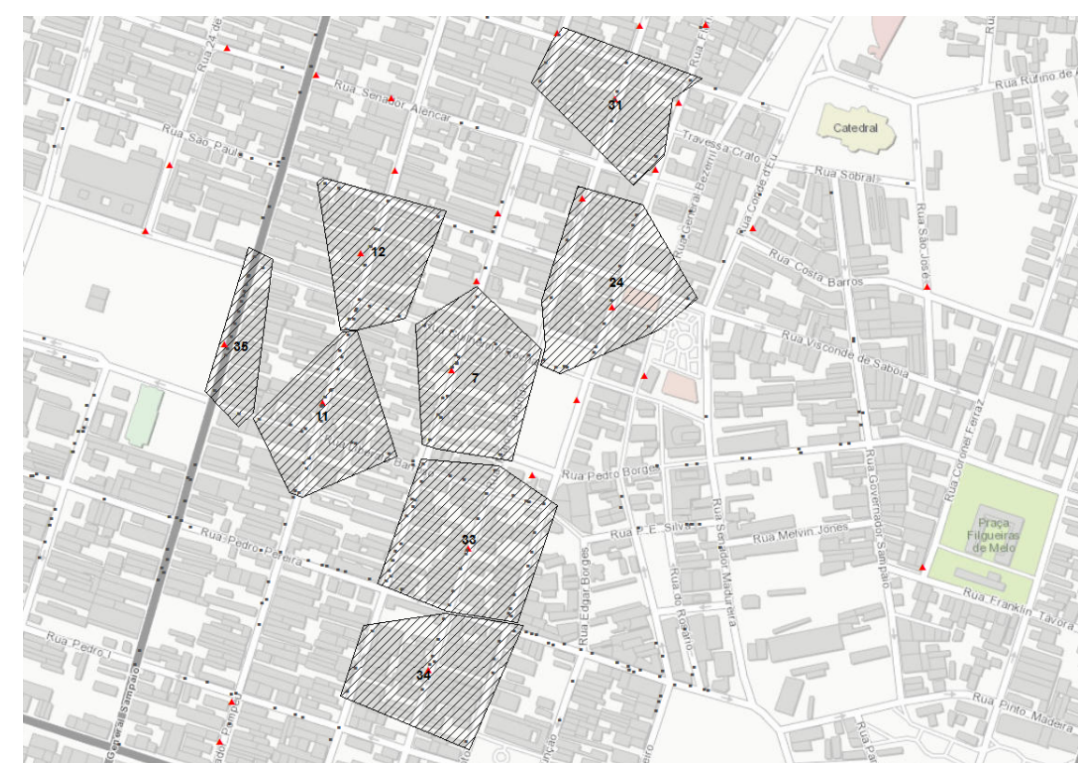

Figure 5: Spatial configuration of loading/unloading spaces - Scenario 4

\subsection{Analysis of results}

The mathematical models presented contributed to the development of a decision support methodology, which enables planners to achieve better regulation of urban freight distribution. The proposed approach facilitates optimal policies for the location of loading-unloading spaces in urban centres, making it a valuable transport policy tool. The following analysis presents a general discussion about the transport policy features of the solutions generated.

One way to improve the service level for the customers is improving allocation of the loading-unloading spaces in the region analysed. This allocation could be obtained increasing the number of parking 
places and improving the geographical distribution of these facilities. Dablanc (2009) points out that an insufficient number of delivery spaces tend to transfer load/unload operations on traffic lanes (double lane). Dablanc (2009) states that in Paris, a guideline imposes a minimum of one delivery bay per every 100 metres of block. Therefore, Scenario 1 is most closely approximates the international policies reported by Dablanc (2009). Except by Dablanc (2009), it is not another references in literature about the density of delivery bay.

In scenarios 2, 3 and 4, where the customers use the infrastructure provided by the government, a policy is needed to utilise the loading-unloading spaces for better operation of the system and to guarantee the turnover for the use of the facilities. This issue must be covered by a policy for freight vehicle parking, which is still lacking in Brazil. According to Dablanc (2009), after discussion between carriers and retailers, such a policy was defined in Paris with a maximum time of 30 minutes for the parking of a vehicle in places subject to high demand.

Another feasible possibility for increasing the customer covering could be the determination of optimised possible places for loading/unloading operations because the proposed approach can optimise the number and the location of these spaces, considering the spaces already existing. A previous optimisation of the location of these candidate spaces could improve the benefits of the methodology presented in this study.

Another problem arising from these scenarios is that cargo should use the same infrastructure used by pedestrians (in this case, the pavements). In the Fortaleza city centre, the pavements are inadequate and the pedestrian movements are high. To guarantee the efficacy of deliveries, greater financial investment in these pavements is essential.

In the light of the results, the model proposed is an important tool for supporting the development of transport policies involving urban freight. As outlined above, although, mentioned in Brazilian legislation, urban freight distribution has not yet received the necessary attention from urban planners. In Fortaleza, legislation that regulates the places for loading/unloading operations needs a technical methodology to define the radius of influence of a given facility. In this case, model proposed in this paper could be useful. Still, the proposed model addresses a concept not previously reported in the literature (quality of service), using same mathematical modelling proposed by Aiura and Taniguchi (2005) and Loureiro et al. (2012) (facility location model).

In this context, a new loading/unloading area must be based on retailer needs and consider the density of spaces around a block. In some cases, major traffic corridors may have spaces to loading/unloading operations, which are incompatible with their traffic flow. Furthermore, some areas are not located directly in front of the customer and, usually, retailers want parking places in front of their stores, although there is no technical criterion for this. Such policy may lead to an excess of loading/unloading places in areas with low volumes of traffic.

The model presented in our study could support the location of loading-unloading spaces as part of a public policy for Brazilian cities. In addition, discussion is essential between public authorities, carriers and retailers to determine a policy for the parking of freight vehicles in urban centres, highlighting the need to streamline transport operations and creating an environment, which advocates cooperative use of infrastructures.

One of the main results of the proposed approach is the generation of several policies with a tradeoff between the coverage radius and the number of uncovered clients. The lower the coverage radius, the greater the number of unattended customers. This result implies that more on-street loading-unloading spaces are required to meet customer demand. New policies for urban goods deliveries, such as urban logistics spaces, or another scheme that minimises the number of trucks in the city and improves the efficiency of deliveries, are also warranted.

The use of geo-referenced information may facilitate the use of the proposed model. In general, this information is not available in Brazilian cities. Thus, maintaining a database of the loading/unloading areas can support urban freight transport and help planners in the decision-making process. 
As consequence of this proposal, management of parking areas and loading/unloading zone using Web solution could be an important evolution to improve urban freight transport. This concept was analysed by McLeod and Cherrett (2011) as case study in Winchester and results show a reduction on delivery time. However, it is not related in literature similar initiative, despite of importance of that to urban freight transport. This solution can be reduce delivery time, freight vehicles movements looking to loading/unloading areas, as mentioned by McLeod and Cherrett (2011). Giuliano et al. (2013) suggest intelligent transport systems as an element of urban freight transport and indicate car-to-infrastructure communication as on application existing but not widely used. The report indicates that application to online reservation for trucks delivery spaces failed due cost and complexity of system in Barcelona. This complexity can be overcome although not reported in the literature. In this case, our proposed model can be incorporate real-time information to improve decision-making process.

Finally, it is important to highlight the computational time evidently had no relevant impact on the decision-making process. For a strategic problem like facility location, computational times of less than 10 minutes are considered insignificant.

\section{CONCLUSIONS}

Optimised management of freight transportation systems may represent significant gains in terms of the cost and quality of service. In this study we presented two formulations for the location of on-street loading-unloading spaces. Literature review indicates that do not have another study addressed this problem considering the quality of service in terms of the cover concept.

A case study based on real data from Fortaleza, Brazil was presented. This case was modelled and solved by the branch-and-bound algorithm, allowing to evaluate the proposed model. Moreover, the proposed scenarios were solved.

The performance of the proposed scenarios was shown to be very good, since optimal solutions could be created in a short computational time. This represents a considerable gain from a practical viewpoint, since there is a substantial decrease in the effort required by the planning process. The minimisation of movements in an urban freight distribution, expressed by the optimal location of on-street loading-unloading spaces, can reduce operational time and cost.

The facility location problem presented has a strong combinatorial nature, being addressed only as an integer linear programming problem and solved by a deterministic approach (branch-and-bound algorithm). However, other important features of the problem such as, for example, the temporal aspects of logistics operations and the probabilistic nature of demand (arrivals and departures of the vehicles) are not considered here and can be incorporate in future studies.

The proposed model assumes that the radius of influence of a given place is a good performance indicator of the service level offered to customers. A bay closer to the client tends to offer better service levels. However, this indicator, although necessary, it is not sufficient to guarantee a high-quality service level. Future studies must consider other operational aspects of the real problem, such as delivery time windows and loading-unloading operations.

Taking into consideration that the largest proportion of the operated freight in the case study analysed comprises general and unitised cargo, operated with traditional procedures, it can reasonably be assumed that the type of business run by clients is not a core variable in the process. However, this conclusion is not general and the variable should be investigated in further studies.

We are currently investigating probabilistic variants of this approach, aimed at responding to critical practical requirements that re"lect the perspectives of the various system stakeholders.

\section{ACKNOWLEDGEMENTS}

The support of the National Council for Scientific and Technological Development (CNPq) is acknowledged and appreciated. 


\section{REFERENCES}

Absi, N.; D. Feillet; T. Garaix e O. Guyon (2012) The city logistics facility location problem. In ROADEF 2012: 13ème congrès annuel de la Société française de Recherche Opérationnelle et d'Aide à la Décision, Angers (France).

Aiura, N. e E. Taniguchi (2005) Planning on-street loading-unloading spaces considering the behavior of pickup-delivery vehicles. Journal of the Eastern Asia Society for Transportation Studies, v. 6, p. 2963-2974. DOI: 10.11175/easts.6.2963

Allen, J.; M. Browne; T. Cherrett e F. McLeod (2008) Review of UK Urban Freight Studies. Green logistics project. London, University of Westminster and University of Southampton.

Antun, J. P.; A. Lozano; R. Hernandéz; R. Alarcón e E. Taniguchi (2007) New trends on physical distribution logistics in Mexico City Metropolitan Area. In: Fifth International Conference on City Logistics, Crete Island (Greece).

BESTUFS (2007) Good practice guide on urban freight transport. Rijswijk, Netherlands, Bestufs.

Boussier, J. M.; T. Cucu; L. Ion e D. Breuil (2010) Simulation of goods delivery process. In 8th International Conference on Logistics and SCM Research. Bordeaux (France).

Brasileiro, L. A.; T. A. Rosin; C. F. Ascenção e G. F Marrafão (2014) Parking for loading and unloading vehicles in urban area. International Journal of Latest Research in Science and Technology, v. 3, n. 5, p. 140-144.

Browne, M.; M. Piotrowska; A. Woodburn e J. Allen (2007) Literature Review WM9: Part I — Urban Freight Transport. London: University of Westminster.

CIVITAS (2010) Cleaner and better transport in cities. Policy advice note: Logistics and freight transportation.

Comi, A.; P. D. Site; F. Filippi e A. Nuzzolo (2012) Urban freight transport demand modelling: a state of the art. European Transport, v. 51, n.7, p. 1-17.

Crainic, T. G.; M. Gendreau e J. Y. Potvin (2009) Intelligent freight-transportation systems: assessment and the contribution of operations research. Transportation Research Part C, v.17, n.6, p. 541-557. DOI: 10.1016-j.trc.2008.07.002

Crainic, T. G.; N. Ricciardi e G. Storchi (2004) Advanced freight transportation systems for congested urban areas. Transportation Research Part C, v. 12, n.2, p. 119-137. DOI: 10.1016-j.trc.2004.07.002

Czerniak, R. J.; J. S. Lahsense e A. Chatterjee (2000) Urban freight movement - What form will it take? Transportation in the New Millennium: State of the Art and Future Directions. Washington, DC, Transportation Research Board.

Dablanc, L. (2007) Goods transport in large European cities: Difficult to organize, difficult to modernize. Transportation Research Part A, v. 41, n.3, p. 280-285. DOI: 10.1016-j.tra.2006.05.005

Dablanc, L. (2009) Freight transport for development toolkit: urban freight. Washington, DC,The World Bank.

Dasburg, N. e J. Schoemaker (2006) D5.2 Quantification of Urban Freight Transport Effects. II. Best urban freight solutions II. Technical Report.

Facchini, D. (2006) Analysis of the Perception of Actors Involved in Urban Freight Transport in Porto Alegre. Dissertation. Federal University of Rio Grande do Sul, Porto Alegre.

Figliozzi, M. A. (2007) Analysis of the efficiency of urban commercial vehicle tours: data collection, methodology, and policy implications. Transportation Research Part B, v. 41, n. 9, p. 1014-1032. DOI: 10.1016-j.trb.2007.04.006

Jaller, M.; J. Holguín-Veras e S. D. Hodge (2013) Parking in the city: challenges for freight traffic. Transportation Research Record, 2379 n.1, p. 46-56. DOI: 10.3141/2379-06.

Janet, H. F. (2004) On-street parking in Hong Kong. Dissertation (Transport Policy and Planning). University of Hong Kong, Hong Kong.

Klose, A. e A. Drexl. (2005) Facility location models for distribution system design. European Journal of Operational Research, 162, p. 4-29, 2005. DOI: 10.1016/j.ejor.2003.10.031.

Larson, R. C. e A. R. Odoni (1981) Urban operations research. Englewood Cliffs, NJ: Prentice-Hall.

Lima, A. C. B.; D. C. Holanda; R. A. Lopes e N. G. S. (2005) Considerations of implementing urban distribution centers: the case of Fortaleza. In XIX Congresso Brasileiro de Pesquisa e Ensino em Transportes, Recife (Brazil).

Loureiro, S. A.; C. L. Barbosa e O. F. Lima Junior (2012) Procedure for location and allocation of loading and unloading spaces in urban centers. In XXVI Congresso Nacional de Pesquisa e Ensino em Transportes. Joinville (Brazil)

Marcucci, E. e E. Musso (2010) Urban Freight Modelling and Policy Analysis. In Van de Voorde, E.; T. Vanelslader (eds.), Applied transport economics: A management and policy perspective. Antwerp, de Boeck.

McLeod, F. e T. Cherrett (2011) Loading bay booking and control for urban freight. International Journal of Logistics: Research and Applications, v. 14, n.6, p. 385-397. DOI: 10.1080-13675567.2011.641525

Munuzuri, J.; J. Larraneta; L. Onieva e P. Cortés (2005) Solutions applicable by local administrations for urban logistics improvement. Cities, v. 22, n.1, p. 15-28. DOI: 10.1016-j.cities.2004.10.003

Giuliano, G.; O'Brien, T.; Dablanc, L. e K. Holliday (2013) Synthesis of freight research in urban transportation planning. Project NCFRP v. 36, n.5. DOI: $10.17226 / 22573$.

OECD (2003). Delivering the goods: 21st century challenges to urban goods transports. Paris, OECD.

Ogden, K. W. (1992) Urban goods movement: a guide to policy and planning. England, Ashgate.

Oliveira, L. K.; A. S. Braga e B. R. A. Abreu (2010) Relevant Attributes in Overnight Goods Delivery: Researchers', Transporters' and Retailers' Preference in Urban Distribution. In: 12th WCTR, July 11-15, 2010, Lisbon, Portugal.

Oliveira, L. K. (2014) Diagnosis of loading and unloading spaces for urban freight distribution: a case study in Belo Horizonte. Journal of Transport Literature, v. 8, n.1, p. 178-209. DOI: 10.1590-S2238-10312014000100009 [in Portuguese]. 
Oliveira, L. K. e V. A. Correia (2014) Proposed methodology to evaluate the benefits of an urban distribution center for mitigation of city logistics problems. Journal of Transport Literature, v. 8, n. 4, p. 109-145. DOI: 10.1590-2238-1031.jtl.v8n4a5 [in Portuguese].

Oliveira, L. K. e E. D. Guerra (2014) A diagnosis methodology for urban goods distribution: a case study in Belo Horizonte City (Brazil). Procedia - Social and Behavioral Sciences, v. 125, n.20, p. 199-211. DOI: 10.1016-j.sbspro.2014.01.1467

Pivo, G.; D. Carslon; M. Kitchen e D. Billen (2002) Learning from truckers: truck drivers' views on the planning and design of urban and suburban centers. Journal of Architectural and Planning Research, v. 19, n.1, p.12-29. D0I: 10.1.1.641.747.

ReVelle, C. e H. A. Eiselt (2005) Location analysis: a synthesis and survey. European Journal of Operational Research, n. 165, p. 1-19. DOI: 10.1016/j.ejor.2003.11.032.

Schroeder, S.; M. Zilske; G. Liedtke e K. Nagel (2014) Towards a multi-agent logistics and commercial transport model: the transport service provider's view. Procedia - Social and Behaviorial Sciences, n. 39, p. 649-663. D0I: 10.1016j.sbspro.2012.03.137

Sittipong, D.; L. Chulin e R. Pongvuthithum (2014) Applied p-median and p-center algorithms for facility location problems. Expert Systems with Applications, n. 41, p. 3596-3604. DOI: 10.1016/j.eswa.2013.11.046.

Tamagawa, D.; E. Taniguchi e T. Yamada (2010) Evaluating city logistics measures using a multi-agent model. Procedia - Social and Behavioral Sciences, n. 2, p. 6002-6012. DOI: 10.1016-j.sbspro.2010.04.014.

Taniguchi, E. e R. E. C. M. van der Heijden (2000) An evaluation methodology for city logistics. Transportation Reviews, v. 20, n. 1, p. 65-90. DOI: 10.1080-014416400295347.

Taniguchi, E. e D. Tamagawa (2005) Evaluating city logistics measures considering the behavior of several stakeholders. Journal of the Eastern Asia Society for Transportation Studies, n. 6, p. 3062-3076. DOI: 10.1.1.583.7868.

Taniguchi, E.; R. G. Thompson e Y. Tadashi (2003) Predicting the effects of city logistics schemes. Transport Reviews, v. 23, n. 4, p. 489-515. DOI: 10.1080-01441640210163999.

Taniguchi, E. (2012) Concept and best practices of city logistics. International Transport Forum. Lecture. Leipzing, 2 may 2012.

Taniguchi, E.; R. G. Thompson e T. Yamada (2014) Recent trends and innovations in modelling city logistics. Procedia - Social and Behavioral Sciences, n. 125, p. 4-14. DOI: 10.1016/j.sbspro.2014.01.1451.

Taniguchi, E.; R. G. Thompson; T. Yamada e H. R. V Duin (2001) City logistics: network modelling and intelligent transport systems. Oxford, Pergamon.

Visser, J.; A. Binsbergen e T. Nemoto (1999) Urban freight transport policy and planning. First International Symposium on City Logistics, Cairns, Australia. 